This item was submitted to Loughborough's Research Repository by the author.

Items in Figshare are protected by copyright, with all rights reserved, unless otherwise indicated.

\title{
Wheel-rail profile condition monitoring
}

PLEASE CITE THE PUBLISHED VERSION

http://dx.doi.org/10.1049/ic.2010.0448

PUBLISHER

(c) IEEE

VERSION

AM (Accepted Manuscript)

LICENCE

CC BY-NC-ND 4.0

REPOSITORY RECORD

Ward, Christopher P., Roger M. Goodall, and Roger Dixon. 2019. "Wheel-rail Profile Condition Monitoring”. figshare. https://hdl.handle.net/2134/6639. 
This item was submitted to Loughborough's Institutional Repository (https://dspace.lboro.ac.uk/) by the author and is made available under the following Creative Commons Licence conditions.

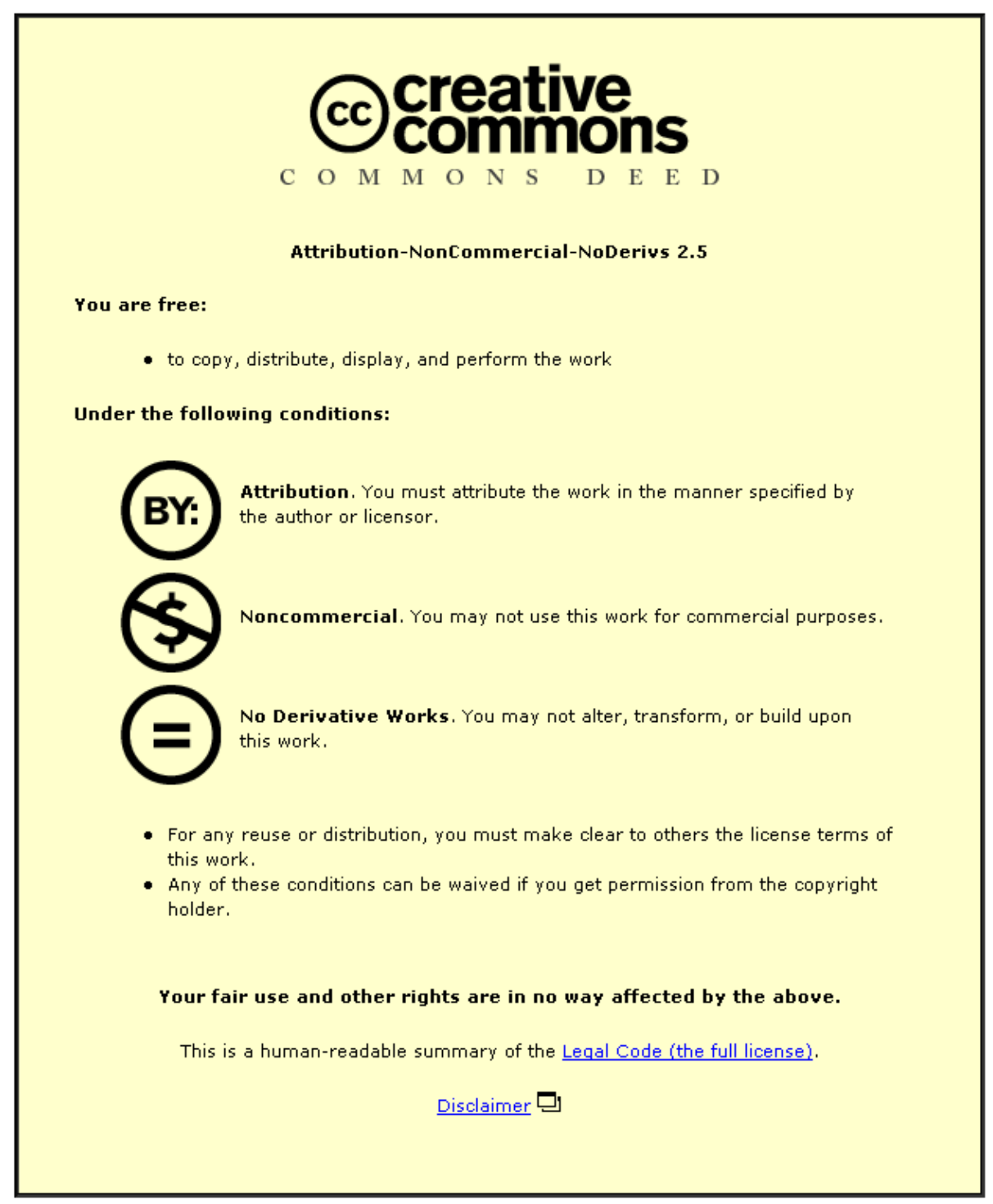

For the full text of this licence, please go to: http://creativecommons.org/licenses/by-nc-nd/2.5/ 


\title{
Wheel-Rail Profile Condition Monitoring
}

\author{
Christopher P. Ward* Roger M. Goodall* Roger Dixon* \\ * Department of Electronic and Electrical Engineering, Loughborough \\ University, Loughborough, Leicestershire, LE11 3TU, UK(e-mail: \\ c.p.ward@lboro.ac.uk; r.m.goodall@lboro.ac.uk; r.dixon@lboro.ac.uk)
}

\begin{abstract}
Increased railway patronage worldwide is putting pressure on rolling stock and infrastructure to operate at higher capacity and with improved punctuality. Condition monitoring is seen as a contributing factor in enabling this and is highlighted here in the context of rolling stock being procured with high capacity data buses, multiple sensors and centralised control. This therefore leaves scope for advanced computational diagnostic concepts. The rail vehicle bogie and associated wheelsets are one of the largest and most costly areas of maintenance on rolling stock and presented here is a potential method for real time estimation of wheel-rail contact wear to move this currently scheduled based assessment to condition based assessment. This technique utilises recursive 'grey box' least squares system identification, used in a piecewise linear manner, to capture the strongly discontinuous nonlinear nature of the wheel-rail geometry.
\end{abstract}

Keywords: Accelerometers, Fault Diagnosis/Detection, Kalman Filters, Nonlinear Systems, Piecewise Linear Analysis, Recursive Least Squares, Railways, Vehicle Dynamics

\section{INTRODUCTION}

Increased patronage of railways worldwide in the past two decades has put pressure on rolling stock and engineering infrastructure to operate at a higher capacity and with increased punctuality. This therefore creates a demand on maintenance systems to reduce the time rolling stock is out of service due to condition checks and regular servicing. Contemporary trains are being built with high capacity communication buses and numerous sensors at important locations on the vehicle. This means there is scope for the application of advanced numerical methods for condition monitoring of key components in real time.

One such component is the railway vehicle bogie and its associated wheelsets, consisting of two wheels solidly fixed to an axle. This system is responsible for one of the largest areas of maintenance costs of the entire system and is therefore one of the key targets for condition monitoring. This paper covers; context of wheel-rail profile estimation; development of simulation models that include gauge width variation with the use of disturbance signals more representative of the frequency content of real track geometry; and development of a recursive identification process using a linear piecewise approach to identify rolling radii and contact angles of the wheel-rail interaction instead of the effective conicity. This last point was previously briefly described in Ward et al. (2010) and is expanded here. Further discussion is made of: a potential looped track disturbance estimation with geometry estimation concept; signal frequency content analysis of different wear states of wheelsets along a section of track; and the potential use of creep force estimation to determine the condition of the wheel-rail interface, Charles et al. (2008c).

This work carries on research performed in various sources to determine the wheel-rail profile. Initially Li et al. (2003), Li et al. (2004) and Li et al. (2006) showed that con- dition monitoring of suspension components such as secondary dampers can be achieved in real time using RaoBlackwellised Particle Filters (RBPF). This was less successful at monitoring the condition of wear of the wheelset in combination with the rail, known as a linearised effective conicity function, $\lambda$. Further investigations of linear conicity estimation were covered in Selamat and Yusof (2009), with the limitation that the model was linear and that the lateral rail irregularity was known.

Ideas for the estimation of a nonlinear conicity were explored initially in Charles et al. (2008c) using Extended Kalman-Bucy Filtering (EKBF). Later Charles et al. (2008b) and Charles et al. (2008a) used a Piecewise Cubic Polynomial (PCP) function in a least squares identification of the nonlinear conicity. The Kalman filter technique had weaknesses at larger relative displacements of the wheelset to the rail and the system identification method required a knowledge of the exact input to the system, the lateral track disturbance $d$. This last point may be unfeasible in application or may require estimation.

\section{WHEELSETS AND CURRENT PRACTICE}

Railway vehicles' wheelsets and how they interact with the railhead are the most fundamental component of a railway vehicle. Two coned and flanged wheels connected solidly to a central shaft provide: straight line guidance to negate the effect of stochastic lateral rail irregularities; cornering performance; braking traction; accelerative traction; and ride characteristics, Iwnicki (2006). Therefore, the condition of these components is of safety critical importance for the operation of the whole system. If the geometry of the wheelset in combination with that of the railhead moves out of allowable tolerance, the rail vehicle can become dynamically unstable and potentially cause vehicle derailment, Wickens (2003). This relationship is 
highly nonlinear as the wheel treads are not perfectly coned and the railheads are not point contact, but domed, an example of which is shown in Figure 1.

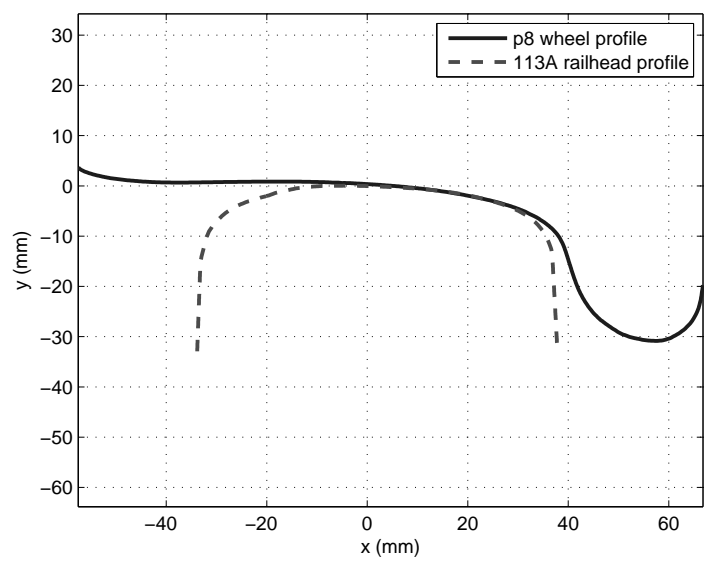

Fig. 1. Wheel profile and railhead cross section

At present, the level of wear in the wheel tread and the railhead are monitored separately with the use of physical measuring devices, such as the MiniProf system, Greenwood-Engineering (2010). This is time consuming, costly and could potentially miss a wheelset or railhead in dangerous condition in-between inspection intervals. Therefore, a system that can detect the level of wear in the wheel-rail contact geometry in real-time is highly desirable. This would make use of cost effective and reliable inertial sensors positioned around the bogie system, with processing performed by advanced filtering.

Condition monitoring is currently becoming more prevalent in rail vehicles. They are being manufactured with multiple sensors, high capacity communication buses and powerful processing capability. One such system in operation is Bombardier Transportation Orbita, Bombardier (2010), which followed trends set in the aerospace and automotive industries where knowledge of fleet condition can be built up through health monitoring systems. The ideas proposed here could be integrated into such a system.

\section{WHEELSET AND VEHICLE MODELS}

The research presented is in the proof of concept stage and so was initially developed using a simple model for simulation, consisting of a single wheelset and single suspended mass (Figure 2). As the work progresses more complex models will be used. Due to minimal coupling between lateral, longitudinal and vertical planes, the wheelset dynamics are considered with only lateral displacement, yaw rotation and roll rotation, with the suspended mass containing only lateral displacement dynamics. A simplified nonlinear model is taken from Garg and Dukkipati (1984), where the equation for the lateral dynamics of the wheelset is

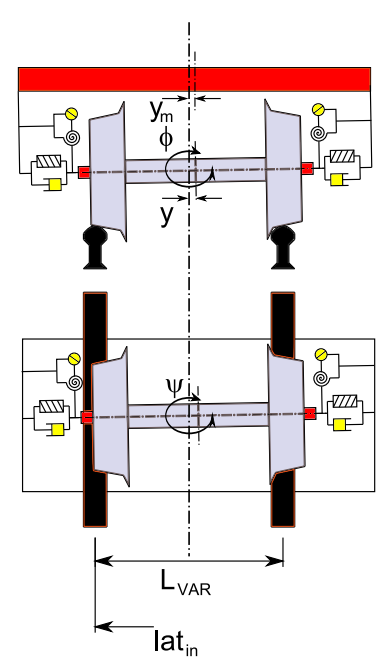

Fig. 2. Wheelset and mass model

$$
\begin{aligned}
m \ddot{y} & +\frac{2 f_{22}}{V}\left(\dot{y}+\frac{\left(r_{L}+r_{R}\right)}{2} \dot{\phi}-V \psi\right) \\
+ & 2 f_{11}\left(1-\frac{\left(r_{L}+r_{R}\right)}{2 r_{0}}\right) \psi \\
& +2 f_{23}\left(\frac{\dot{\psi}}{V}-\frac{\left(\delta_{L}-\delta_{R}\right)}{2 r_{0}}\right) \\
+ & W\left(\frac{\left(\delta_{L}-\delta_{R}\right)}{2}+\phi\right)=F_{s y}
\end{aligned}
$$

which consists of the longitudinal creep force, lateral creep force, lateral/spin creep force and gravitational creep force. The yaw dynamics equation for the wheelset is

$$
\begin{gathered}
I \ddot{\psi}+I_{w y} \frac{V}{r_{0}} \dot{\phi}+\frac{2 l^{2} f_{11}}{r_{0}}\left(\frac{\left(r_{L}-r_{R}\right)}{2 l}\right) \\
-\frac{2 f_{23}}{V}\left(\dot{y}+\frac{\left(r_{L}+r_{R}\right)}{2} \dot{\phi}-V \psi\right) \\
+2 l^{2} f_{11} \frac{\dot{\psi}}{V}-2 f_{33} \frac{\left(\delta_{L}-\delta_{R}\right)}{2 r_{0}} \\
-l W \frac{\left(\delta_{L}+\delta_{R}\right)}{2} \psi+2 f_{33} \frac{\dot{\psi}}{V}=M_{s \psi}
\end{gathered}
$$

which consists of the roll moment, longitudinal creep moment, lateral/spin creep moment, spin creep moment and the gravitational stiffness moment. The equation for the lateral dynamics of the suspended mass is

$$
\ddot{y}=\frac{1}{m_{m}}\left(F_{s y}\right)
$$

the lateral suspension forces is

$$
F_{s y}=k_{y}\left(y_{m}-y\right)+f_{y}\left(\dot{y}_{m}-\dot{y}\right)
$$

and the suspension yaw force is

$$
M_{s \psi}=-k_{\psi} \psi-f_{\psi} \dot{\psi}
$$

Parameters and states for all of the equations are given in Table A.1.

The significant nonlinearities in the equations are in the form of static geometric relationships of the rolling radii and contact angles, $r_{L} r_{R} \delta_{L} \delta_{R}$. These are calculated for specific wheel-rail combinations by a Newton-Raphson iterative process, Wickens (2003), and are function of the relative displacement of the wheelset to the railhead, $(y-$ d). Example profiles for a P8 wheel profile and a $113 \mathrm{~A}$ 
rail head are shown in Figure 3. This shows the extreme discontinuous nature of the relationships and is one of the key elements in making their estimation especially complex. It should also be noted that these equations are partially linearised by using Kalker coefficients for the friction values, Kalker (1967), but in reality this is not the case and presents another significant source of nonlinearity.
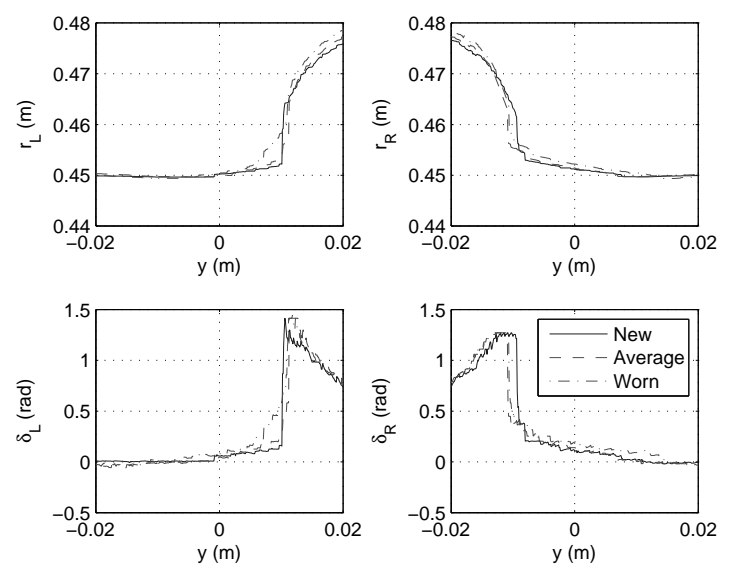

Fig. 3. Wheel-rail contact geometries

Modelling in previous studies have neglected the influence of gauge width variation in the model, where this was assumed to be a negligible effect, Charles et al. (2008c). Investigation has shown this is a significant dynamic component. This has been coupled with using track inputs and gauge width variations from real recorded data instead of using filtered white noise sources, as the latter can lead to poor correlation between models and reality due to frequency biasing, Evans and Berg (2009). Therefore using inputs from a track recording car on the Paddington to Bristol line, with magnitudes corresponding to track alignment regulations defined in RSSB (2007), Figure 4 shows collected data of the rolling radii sums $\left(r_{L}+r_{R}\right)$ and how this is not a singular valued function of the relative lateral displacement, but is instead distributed over a bounded uncertain region. Also due to the asymmetry

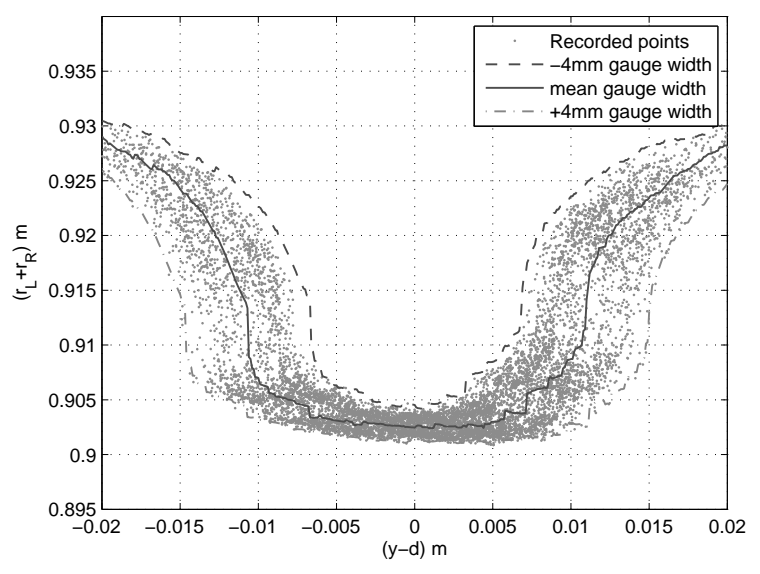

Fig. 4. Gauge width uncertainty effect

in the left and right geometry, the gauge width variation can laterally excite the system, though this is a secondary effect.

It is also assumed that ideal inertial sensors are present in the axleboxes that can measure the lateral acceleration, yaw acceleration and roll acceleration of the wheelset. The suspended mass is assumed to be fitted with a lateral accelerometer. It is noted that inertial sensors will require a degree of filtering due to the presence of noise and will also drift from their offset in time, so the quality of information gathered in simulation can not be expected in reality, Weston et al. (2006). An assumption is also made that the lateral alignment and the gauge width variation of the track is known. These later points mean that the current algorithm remains to be proved in practice.

\section{PIECEWISE LINEAR IDENTIFICATION}

Previous approaches to this problem, as highlighted earlier used: an RBPF to estimate a linearised conicity value; augmented state EKBF to estimate a nonlinear conicity function; and system identification to identify a nonlinear conicity function. These were applied to simplified models and the conicity was a smooth generic shape combining a S1002 wheel tread and UIC60 railhead. When applied to a nonlinear model with discontinuous nonlinear geometries and richer dynamics, they failed to produce satisfactory results. Therefore it was deemed appropriate to perform a number of linear identifications around small regions of the wheel-rail displacement, building a table of values rather than a single nonlinear function. This also makes use of recursive 'grey box' weighted least squares algorithm so that the process can be used more efficiently in real time. However there still remains the issue of a measurement of the track alignment being required.

This section therefore introduces: the recursive 'grey box' least squares identification scheme and how this is applied to the geometry estimation problem; the method of data re-ordering to perform discrete range estimations; and the basic block algorithm of how these concepts are assimilated to produce an estimation of the nonlinear wheel-rail contact geometry

\section{1 'Grey box' weighted recursive least squares}

A standard regressor or state model can be defined as

$$
\widehat{y}=X^{T} \theta
$$

where $y$ is the measured output of the system, $X$ is a matrix of measured state values and $\theta$ is the matrix of unknown parameters. The estimation of the unknown parameters can be defined by the standard 'black box' ordinary least squares (OLS) equation, Hsia (1977), Ljung (1999), Söderström and Stoica (1994) as

$$
\theta=\left(X^{T} X\right)^{-1} X^{T} y
$$

If there is some knowledge of the system generated through modelling or simulation and there are some known parameters, a new regressor or state equation can be defined as

$$
\widehat{y}=X^{T} \theta+\Omega
$$

where $\Omega$ is the known combinations of the parameters and regressor or state output vectors. The 'grey box'OLS algorithm becomes

$$
\widehat{\theta}=\left(X^{T} X\right)^{-1}\left(X^{T} y-X^{T} \Omega\right)
$$


This format is a 'block' identification, where all of the data collected is used to determine the unknown parameters. In this application data from the system will be collected in real time and as such an updating process is needed that will adapt with time as new data is collected. The 'black box' and 'grey box' OLS algorithms can be applied in such as manner, Aström (1989). A weighting factor can also be added to 'forget' previous measurements, thus being more or less receptive to new data. Initial conditions for the 'grey box' recursive least squares version of the algorithm are set as

$$
\begin{gathered}
P_{(0)}=\left(X_{(0)}^{T} X_{(0)}\right)^{-1} \\
\theta_{(0)}=P_{(0)}\left(X_{(0)}^{T} y_{(0)}-X_{(0)}^{T} \Omega_{(0)}\right)
\end{gathered}
$$

where $X_{(0)}$ is the matrix of state values up to the start of the identification process, $y_{(0)}$ is the initial output vector and $\theta_{(0)}$ is the initial least squares estimation. The estimation loop is then performed recursively as data is added to the $X$ matrix as

$$
\begin{gathered}
\gamma_{(i)}=\frac{1}{W+X_{(i)}^{T} P_{(i-1)} X_{(i)}} \\
P_{(i)}=\left(P_{(i-1)}-\gamma_{(i)} P_{(i-1)} X_{(i)}^{T} X_{(i)} P_{(i-1)}\right) \frac{1}{W} \\
\theta_{(i)}=\theta_{(i-1)}+\left(\gamma _ { ( i ) } P _ { ( i - 1 ) } X _ { ( i ) } ^ { T } \left(\left(y_{(i)}-\Omega_{(i)}\right)\right.\right. \\
\left.\left.-\left(X_{(i)} \theta_{(i-1)}\right)\right)\right)
\end{gathered}
$$

where $0<W \leq 1$ is the updating weighting factor and $i$ is the number of the iteration. This format also saves computational expense as only the latest added values are acted upon rather than the entire data set.

In this application each estimation is performed using two multiple-input-single-output identifications. The first is a re-arrangement of the lateral wheelset dynamics (Equation 1 ) to make the lateral acceleration $\ddot{y}$ the subject, from this the known parameter equation becomes

$$
\begin{aligned}
\Omega_{1} & =\left(-\frac{2 f_{22}}{m v}-\frac{f_{y}}{m}\right) \dot{y}+\left(-\frac{k_{y}}{m}\right) y+\left(\frac{f_{y}}{m}\right) \dot{y}_{m} \\
& +\left(\frac{k_{y}}{m}\right) y_{m}+\left(-\frac{2 f_{23}}{m v}\right) \dot{\psi}+\left(-\frac{W}{m}\right) \dot{\phi}
\end{aligned}
$$

and the $X$ matrix becomes

$$
X_{1}=[\psi, \dot{\phi}, 1]
$$

The second estimation uses the wheelset yaw dynamics (Equation 2) in the form of the yaw acceleration $\ddot{\psi}$, from which the known parameter equation becomes

$$
\Omega_{2}=\left(-\frac{2 f_{23}}{I v}\right) \dot{y}+\left(-\frac{2 l^{2} f_{11}}{I v}-\frac{2 f_{33}}{I v}-\frac{f_{\psi}}{I}\right) \dot{\psi}
$$

and the corresponding $X$ matrix is

$$
X_{2}=[\psi, \dot{\phi}, 1]
$$

Estimates of the corresponding parameters can then be manipulated to determine the parameter combinations $\left(r_{L}+r_{R}\right),\left(r_{L}-r_{R}\right),\left(\delta_{L}+\delta_{R}\right)$ and $\left(\delta_{L}-\delta_{R}\right)$.

\subsection{Data splitting}

The recursive least squares estimation of the previous section is applied to discrete sections of data relative to the wheel-rail displacement. Therefore this data first requires ordering from the main data stream. This separation is performed relative to the displacement $(y-d)$, therefore if the data is of the length $n$, the range of the data is defined as

$$
a=\max (y-d)-\min (y-d)
$$

where $b$ is the user defined division size, the number of sections that the data is separated becomes

$$
n=\frac{a}{b}
$$

The data is then partitioned into one of the $n$ bins. If the number of bins is defined as $j=1: n$ and the time interval is defined as $i$, the current collected piece of data $(y-d)_{i}$ is checked to see if

$$
a j>(y-d)_{i}>a(j-1)
$$

If this statement is true the data is stored in bin $j$. Correspondingly the data for all the other states at time $i$ are stored in bins numbered $j$. This process occurs recursively so that as new data is collected it is checked for relative position and stored in the corresponding bin.

This separation of data works here due to the very stiff nature of the system. Meaning that there is very little time delay present and therefore the states of the system match up as the data transitions in and out of the division sections, though inevitably some correlation will be lost.

\subsection{Algorithm}

The following is a step by step algorithm for the wheel-rail profile detection procedure

(1) Begin collecting data

(2) Separate data into bins relative to the wheel-rail displacement $(y-d)$

- Process is continuous as new data is added

(3) When a data bin has reached a threshold level number of data points, begin estimation with data in that bin

(4) Recursively identify unknown parameters using 'grey box' least squares algorithm

- Recursively update the estimation as new data is added to the separation bins

this is also shown in Figure 5.

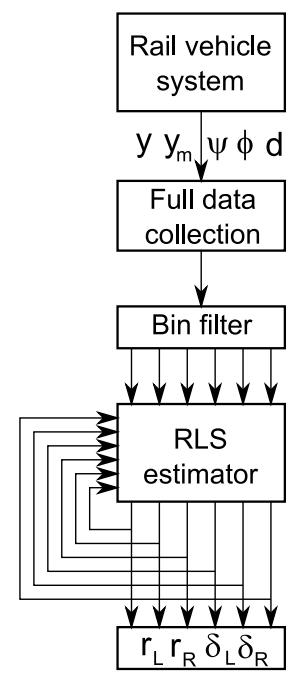

Fig. 5. Algorithm flow chart 


\section{EXAMPLE APPLICATION}

The above algorithm was applied to the single wheelset system and suspended mass in two configurations, the first with no gauge width variation as the second with gauge width variation. Values of the parameters used for the simulation are also shown in Table A.1 where applicable.

Simulations were run with P8 shaped wheelsets in a medium state of wear having covered 117,000 miles on a class 43 power car and a 113A railhead in a new state. The system was excited by lateral misalignment of the railhead with a standard deviation (STD) of approximately $2 \mathrm{~mm}$, and with a gauge width variation also with an STD of approximately $2 \mathrm{~mm}$. Both misalignments were recored on the Paddington to Bristol line using a track recording car.

The estimation was first performed with no gauge width variation present. As expected this produces a good estimation of the model parameters, this is shown in Figure 6 for the rolling radii sums, $\left(r_{L}+r_{R}\right)$. Though not shown, the remaining three geometric combinations also give good correlation.

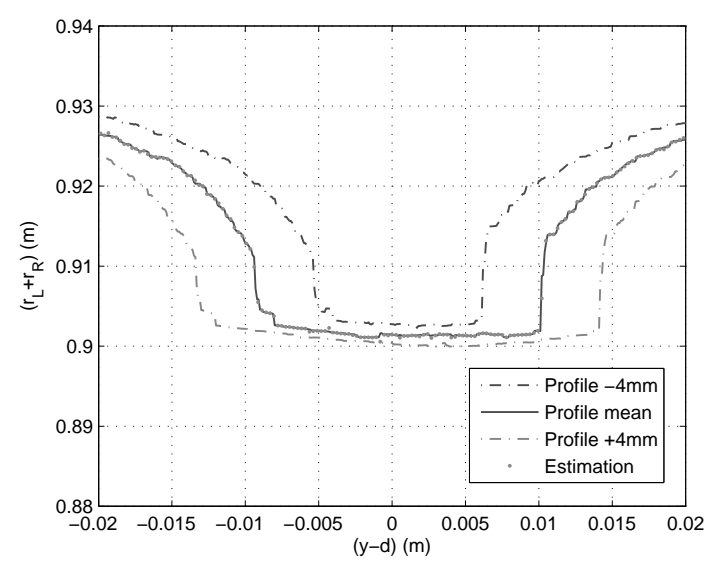

Fig. 6. Estimation with no gauge width variation

The second estimation is performed with gauge width variation in the simulation. This does not produce as good an estimation due to there now being uncertainty in the parameters. Figure 7 shows the estimation again for the rolling radii sums. The estimation points now occupy an estimation space within the boundaries set by the gauge width variation. Although not shown the contact angle sum fails to converge completely. This may be due to the parameter being highly dependent upon knowing the gauge width exactly.

\section{FUTURE WORK AND POSSIBLE APPROACHES}

The main issue with the algorithm highlighted in this paper is the need to know the input irregularity and the gauge width variation. This would be difficult and expensive to practically measure in real time for each wheelset using a vision or laser based system. It is possible that track recording data might be exploited but precise synchronisation means that this is not straight forward. Another possible solution is to estimate the disturbance

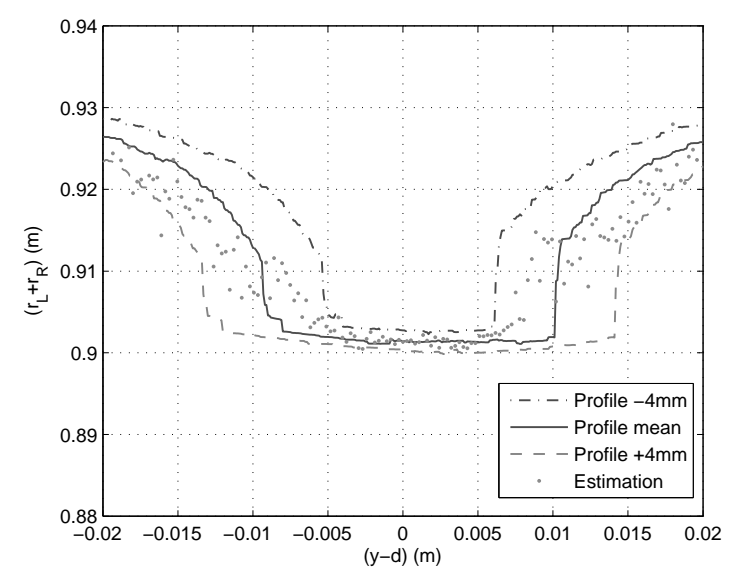

Fig. 7. Estimation with gauge width variation

signal with an assumed geometric formation, then feed this estimate into the identification. This would become a looped process with the disturbance estimation running at a faster rate than the geometric estimation, a schematic of which is shown in Figure 8. However this estimation will

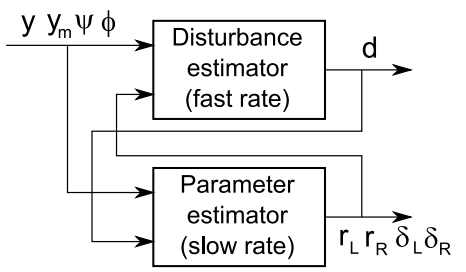

Fig. 8. Looped estimator

also be a highly complex nonlinear algorithm.

To negate the need to have the exact disturbance signal, solutions could rely on a statistical analysis. Initial work has begun to look at the frequency content of raw measured signals for various conditions of wheelsets along the same section of track. This has shown some difference and could therefore be used to build a library that could be referenced against signals collected in operation, therefore giving an indication of the wear state. However this would require a great deal more user input. Similar possibilities are to analyse the force estimation that is proposed for low adhesion estimation, Charles et al. (2008c).

\section{CONCLUSION}

This paper discussed a potential algorithm for the real time estimation of the wheel-rail contact geometry in rail vehicle systems. This interaction is important due to it governing the straight line running stability and cornering performance of rail vehicles. The recursive least squares algorithm proposed uses a series of piecewise linear estimations due to the strongly discontinuous nature of the contact geometry, where the dynamic data is sectioned relative to the wheel-rail displacement. With no gauge width variation this gives excellent correlation with the inputted geometry, but begins to decorrelate when uncertainty in the gauge width is added to the system. The technique also relies upon a knowledge of the track disturbance to perform the estimation that might not be practicably feasible. 
Further proposals were made to negate the problems of track alignment measurement, such as; estimation of the track disturbance using a known geometry; using statistical analysis of measured signals from the wheelset that correspond to specific wear states along a section of track; or using statistical information from the estimation of creep forces in the contact area.

\section{ACKNOWLEDGEMENTS}

The authors would like to thank Rail Research United Kingdom (RRUK) and the Engineering and Physical Science Research Council (EPSRC) who funded this research. Additional thanks to the Rail Technology Unit (RTU) at Manchester Metropolitan University (MMU) who provided track and vehicle data for the study.

\section{REFERENCES}

Aström, K. (1989). Adaptive control. Addison-Wesley, first edition.

Bombardier (2010). Orbita - predictive asset management, the future of fleet maintenance. http://www.bombardier.com/en/transportation/ accessed 7th April 2010.

Charles, G., Dixon, R., and Goodall, R. (2008a). Condition Monitoring Approaches to Estimating Wheel-Rail Profile. In Proceedings of UKACC Control Conference, Manchester.

Charles, G., Goodall, R., and Dixon, R. (2008b). A Least Mean Squared Approach to Wheel-Rail Profile Estimation. In Proceedings of the 4th International Conference On Railway Condition Monitoring.

Charles, G., Goodall, R., and Dixon, R. (2008c). Modelbased condition monitoring at the wheel-rail interface. Vehicle System Dynamics, 46(1), 415-430.

Evans, J. and Berg, M. (2009). Challenges in simulation of rail vehicle dynamics. International Journal of Vehicle Mechanics and Mobility, (8), 1023-1048.

Garg, V. and Dukkipati, R. (1984). Dynamics of Railway Vehicle Systems. Academic Press, first edition.

Greenwood-Engineering (2010). MiniProf - the profile of measuring. http://www.greenwood.dk/miniprof.php accessed 7th April 2010.

Hsia, T. (1977). System Identification, Least-Squares Methods. Lexington Books, first edition.

Iwnicki, S. (2006). Handbook of Railway Vehicle Dynamics. Taylor and Francis, first edition.

Kalker, J. (1967). On the Rolling Contact of Two Elastic Bodies in the Presence of Dry Friction. Ph.D. thesis, Delft University of Technology, Delft, Netherlands.

Li, P., Goodall, R., and Kadirkamanathan, C. (2003). Parameter estimation of railway vehicle dynamic model using rao-blackwellised particle filter. In Proceedings of the seventh European control conference, Cambridge, $U K$.

Li, P., Goodall, R., and Kadirkamanathan, C. (2004). Estimation of parameters in a linear state space model using a rao-blackwellised particle filter. IEE ProceedingsControl Theory and Applications, 151:727-738.

Li, P., Goodall, R., Weston, P., Ling, C., Goodman, C., and Roberts, C. (2006). Estimation of railway vehicle suspension parameters for condition monitoring. Control Engineering Practice, 15:43-55.
Ljung, A. (1999). System Identification, Theory for the User. Prentice Hall, second edition.

RSSB (2007). Track System Requirements GC/RT5021. Rail Safety and Standards Board Limited, third edition.

Selamat, H. and Yusof, R. (2009). Wheel-rail contact parameters estimation for a conical solid-axle railway wheelset using least-absolute error with variable forgetting factor method. In Proceedings of the 2009 IEEE International Conference on Industrial Technology.

Söderström, T. and Stoica, P. (1994). System Identification. Prentice Hall, second edition.

Ward, C., Weston, P., Stewart, E., Li, H., Goodall, R., Roberts, C., Mei, T., Charles, G., and Dixon, R. (2010). Condition monitoring opportunities using vehicle based sensors. Awaiting publication: IMechE proceedings, Part F: Rail and Rapid Transit.

Weston, P., Ling, C., Goodman, C., Roberts, C., Li, P., and Goodall, R. (2006). Monitoring lateral track irregularity from in-service railway vehicles. IMechE proceedings, Part F: Rail and Rapid Transit, 221(RRUK Special Issue), 89-100.

Wickens, A. (2003). Fundamentals of Rail Vehicle Dynamics: Guidance and Stability. Swets and Zeitlinger, first edition.

\section{Appendix A. PARAMETERS AND STATES OF THE WHEELSET MODEL}

\begin{tabular}{|c|c|c|c|}
\hline Parameter & Description & Value & Units \\
\hline$f_{11}$ & longitudinal creep coefficient & $7.44 \mathrm{e} 6$ & $\mathrm{~N}$ \\
\hline$f_{22}$ & lateral creep coefficient & $6.79 \mathrm{e} 6$ & $\mathrm{~N}$ \\
\hline$f_{23}$ & lateral/spin creep coefficient & $13.7 \mathrm{e} 3$ & $\mathrm{Nm}$ \\
\hline$f_{33}$ & spin creep coefficient & 0 & $\mathrm{Nm}^{2}$ \\
\hline$f_{y}$ & lateral damper coefficient & $50 \mathrm{e} 3$ & $\mathrm{Ns} / \mathrm{m}$ \\
\hline$f_{\psi}$ & yaw damper coefficient & 0 & Nms \\
\hline$I$ & wheelset yaw inertia & 700 & $\mathrm{kgm}^{2}$ \\
\hline$I_{w y}$ & wheelset roll inertia & 200 & $\mathrm{kgm}^{2}$ \\
\hline$l$ & half wheelset width & 0.7452 & $\mathrm{~m}$ \\
\hline$m$ & wheelset mass & 1250 & $\mathrm{~kg}$ \\
\hline$m_{m}$ & suspended mass & 8000 & $\mathrm{~kg}$ \\
\hline$k_{y}$ & lateral suspension stiffness & $0.23 \mathrm{e} 6$ & $\mathrm{~N} / \mathrm{m}$ \\
\hline$k_{\psi}$ & yaw suspension stiffness & $2.5 \mathrm{e} 6$ & $\mathrm{Nm}$ \\
\hline$V$ & velocity & 20 & $\mathrm{~m} / \mathrm{s}$ \\
\hline$W$ & wheelset weight & 12263 & $\mathrm{~N}$ \\
\hline$r_{0}$ & nominal rolling radius & 0.45 & $\mathrm{~m}$ \\
\hline$r_{L}$ & left rolling radius & - & $\mathrm{m}$ \\
\hline$r_{R}$ & right rolling radius & - & $\mathrm{m}$ \\
\hline$\ddot{y}$ & lateral acceleration & - & $\mathrm{m} / \mathrm{s}^{2}$ \\
\hline$\dot{y}$ & lateral rate & - & $\mathrm{m} / \mathrm{s}$ \\
\hline$y$ & lateral displacement & - & $\mathrm{m}$ \\
\hline$\delta_{L}$ & left contact angle & - & $\mathrm{rad}$ \\
\hline$\delta_{R}$ & right contact angle & - & $\mathrm{rad}$ \\
\hline$\dot{\phi}$ & wheelset roll rate & - & $\mathrm{rad} / \mathrm{s}$ \\
\hline$\phi$ & wheelset roll angle & - & $\mathrm{rad}$ \\
\hline$\ddot{\psi}$ & wheelset yaw acceleration & - & $\mathrm{rad} / \mathrm{s}^{2}$ \\
\hline$\dot{\psi}$ & wheelset yaw rate & - & $\mathrm{rad} / \mathrm{s}$ \\
\hline$\psi$ & wheelset yaw angle & - & $\mathrm{rad}$ \\
\hline
\end{tabular}

Table A.1. Constants and States for the wheelrail profile estimation 